DOE/ER/13403--5

DE93 013258

\title{
PERFORATED MONOLAYERS
}

Progress Report

July 1, 1990 - December 31, 1992

Submitted By

S. L. Regen

Department of Chemistry, Lehigh University

Bethlehem, Pennsylvania 18015

December 1992

PREPARED FOR THE U.S. DEPARTMENT OF ENERGY CONTRACT NUMBER DE-FG02-85ER 13403 


\section{NOTICE}

This report was prepared as an account of work sponsored by the United States Government. Neither the United States nor the Department of Energy, nor any of their employees, nor any of their contractors, subcontractors, or their employees, makes any warranty, express or implied, or assumes any legal liability or responsibility for the accuracy, completeness, or usefulness of any information, apparatus, produce or process disclosed or represents that its use would not infringe on privately-owned rights.

\section{DISCLAIMER}

This report was prepared as an account of work sponsored by an agency of the United States This report was prepared as an account of work sponsored by an agency thereof, nor any of their employees, makes any warranty, express or implied, or assumes any legal liability or responsibility for the accuracy, completeness, or usefulness of any information, apparatus, product, or process disclosed, or represents that its use would not infringe privately owned rights. Reference herein to any specific commercial product, process, or service by trade name, trademark, manufacturer, or otherwise does not necessarily constitute or imply its endorsement, recommendation, or favoring by the United States Government or any agency thereof. The views and opinions of authors expressed herein do not necessarily state or reflect those of the United States Government or any agency thereof. 


\begin{abstract}
The goal of this research program is to create ultrathin organic membranes that possess uniform and adjustable pores ( $<7 \AA$ diameter). Such membranes are expected to possess high permeation selectivity (permselectivity) and high permeability, and to provide the basis for energyefficient methods of molecular separation. Work that has been carried out over this past contract period has demonstrated the feasibility of using "perforated monolayer"-based composites as molecular sieve membranes. Specifically, composite membranes derived from Langmuir-Blodgett multilayers of the calix[6]arene-based surfactant shown below plus poly[1-(trimethylsilyl)-1propyne] (PTMSP) were found to exhibit sieving behavior towards $\mathrm{H}_{2}, \mathrm{~N}_{2}$ and $\mathrm{SF}_{6}$. The results of derivative studies that have also been completed during this past contract period are also described in this report.
\end{abstract}

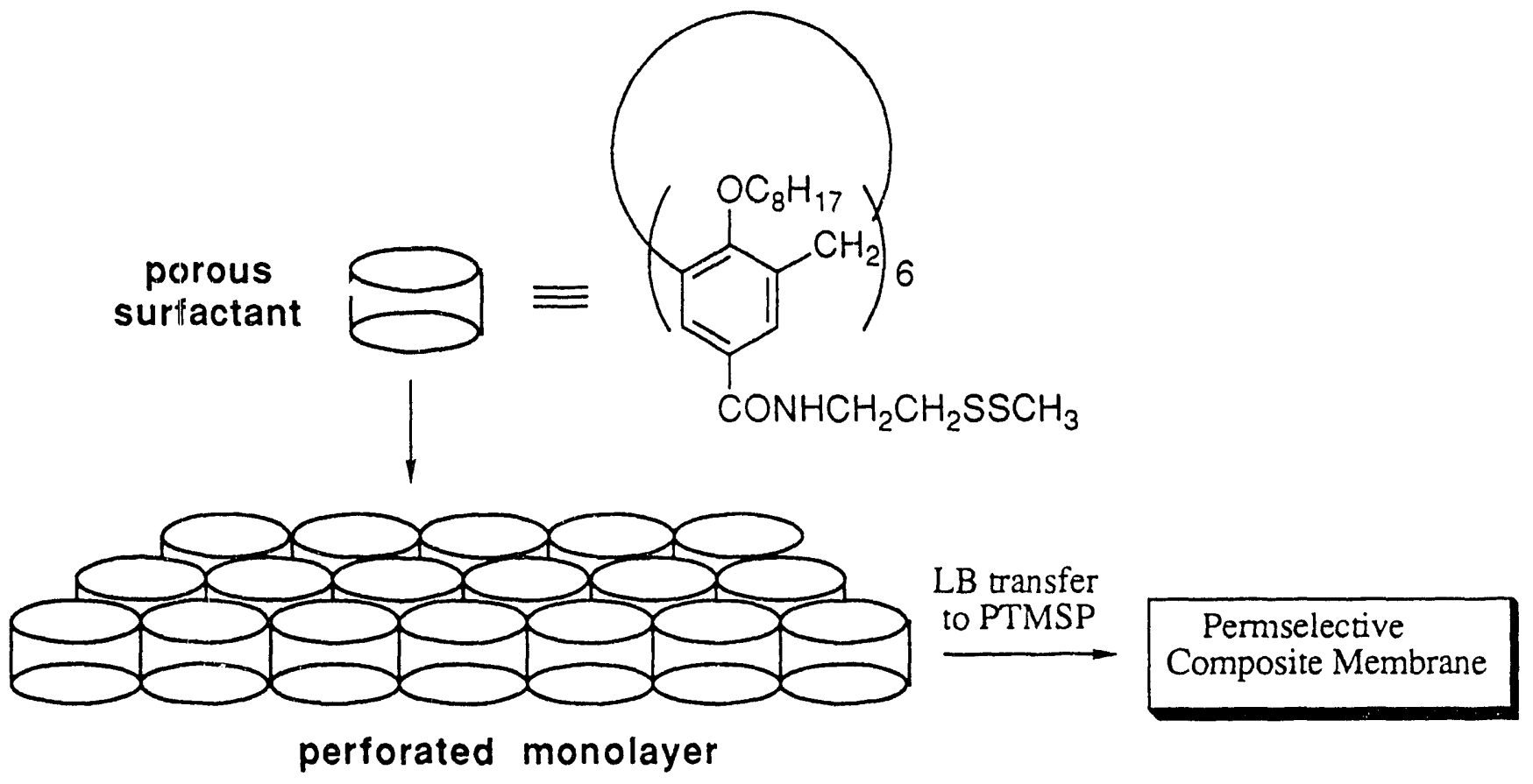




\section{DETAILED REPORT}

I. Porous Polymerizable Surfactants. Four polymerizable calix[6]arene-based surfactants that were chosen as target molecules over this past contract period are shown below (IIV). The carboxylated calix[6]arene (I) was expected to form stable monolayers at the gas-water interface, and to be effectively cross-linked by poly(allylamine) in the aqueous subphase. ${ }^{1} \mathrm{~A}$ hexaamide derivative, $\Pi$, was expected to form cross-linked monolayers upon exposure to ultraviolet light $(254 \mathrm{~nm})$ via disulfide disproportionation. ${ }^{2}$ Based on the ease cf oxidation of thiols to disulfides, the hexathiol-calix[6]arene, III was expected to polymerize in the monolayer state upon exposure to air.3,4 Finally, a styryl-type of calix[6]arene (IV) was chosen as a target molecule because of its expected surfactant properties and photopolymerizability. 5

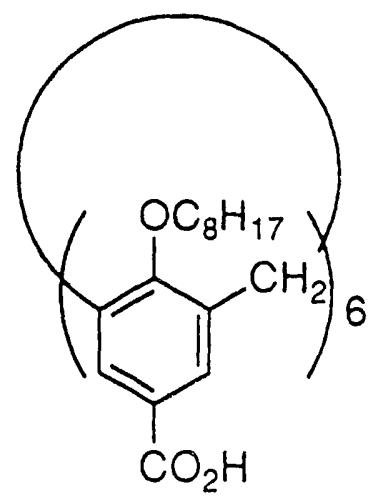

I

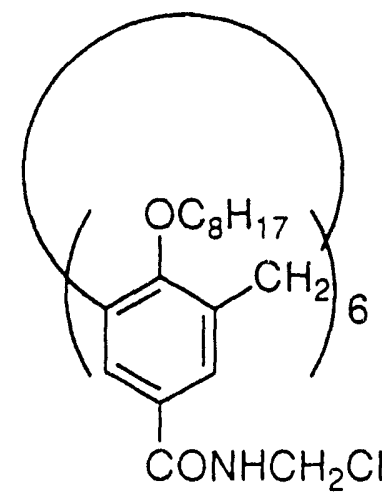

II

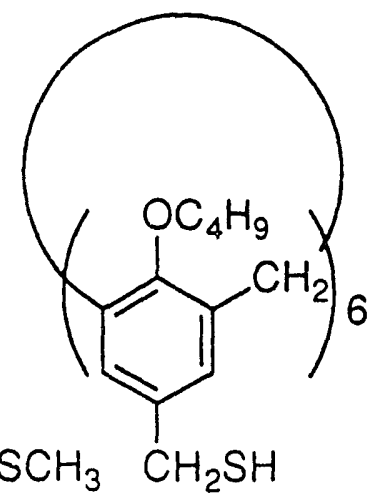

III

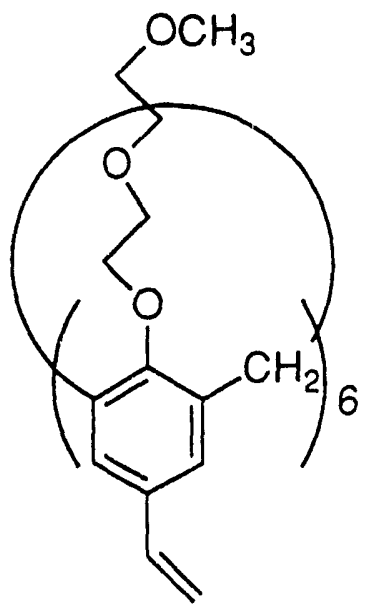

IV

a) Surfactant Synthesis. Alkylation of $37,38,39,40,41,42$-hexahydroxycalix[6]arene with 1-bromooctane, followed by Friedel-Crafts acylation $\left(\mathrm{CH}_{3} \mathrm{COCl}\right)$ and haloform oxidation afforded I. Subsequent conversion to the corresponding acid chloride and condensation with 2methyldithiaethylamine afforded the hexaamide II (Scheme I). The hexathiol calix[6]arene III 


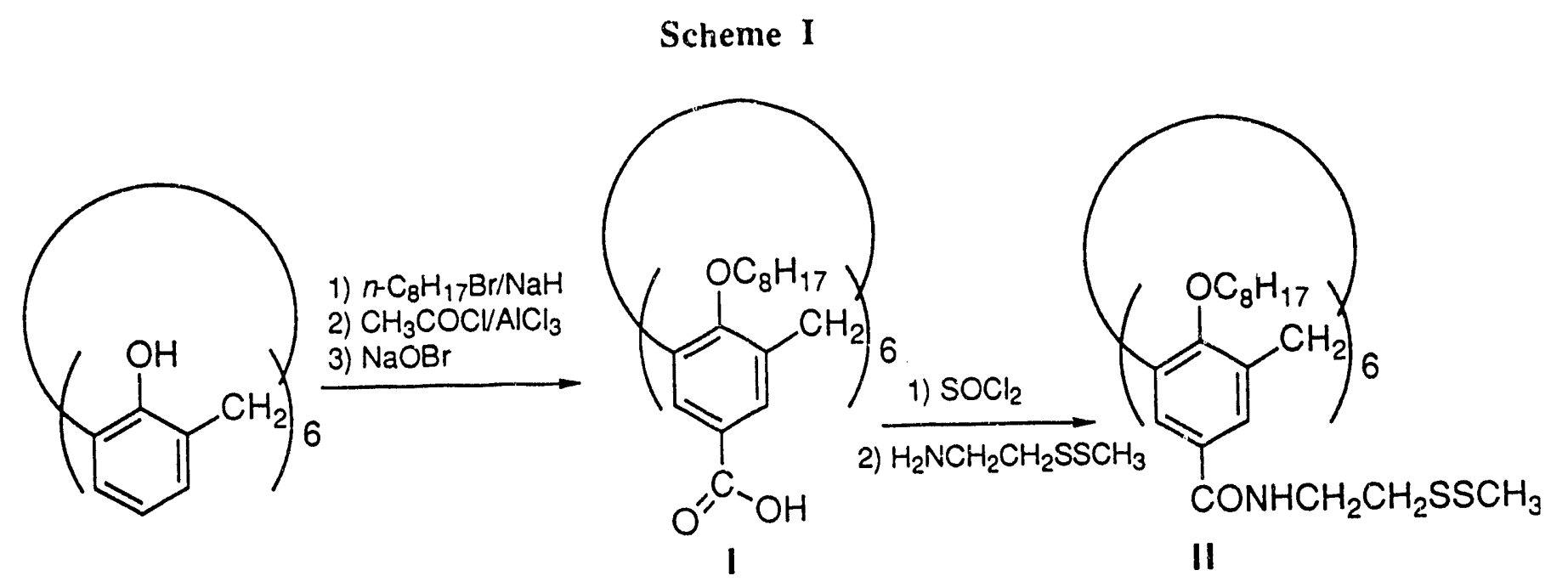

Scheme II

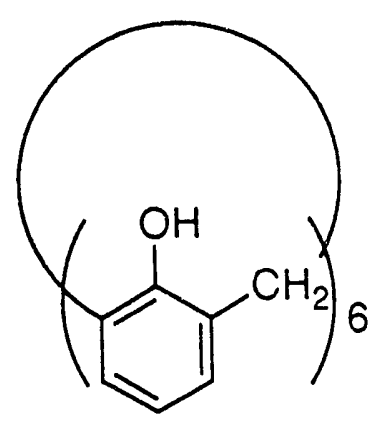

1) $n-\mathrm{C}_{4} \mathrm{H}_{9} \mathrm{Br} / \mathrm{NaH}$

2) $\mathrm{ClCH}_{2} \mathrm{OC}_{8} \mathrm{H}_{17} / \mathrm{SnCl}_{4}$ 3) $\mathrm{KSCOCH} / \mathrm{DMF} / 60^{\circ}$
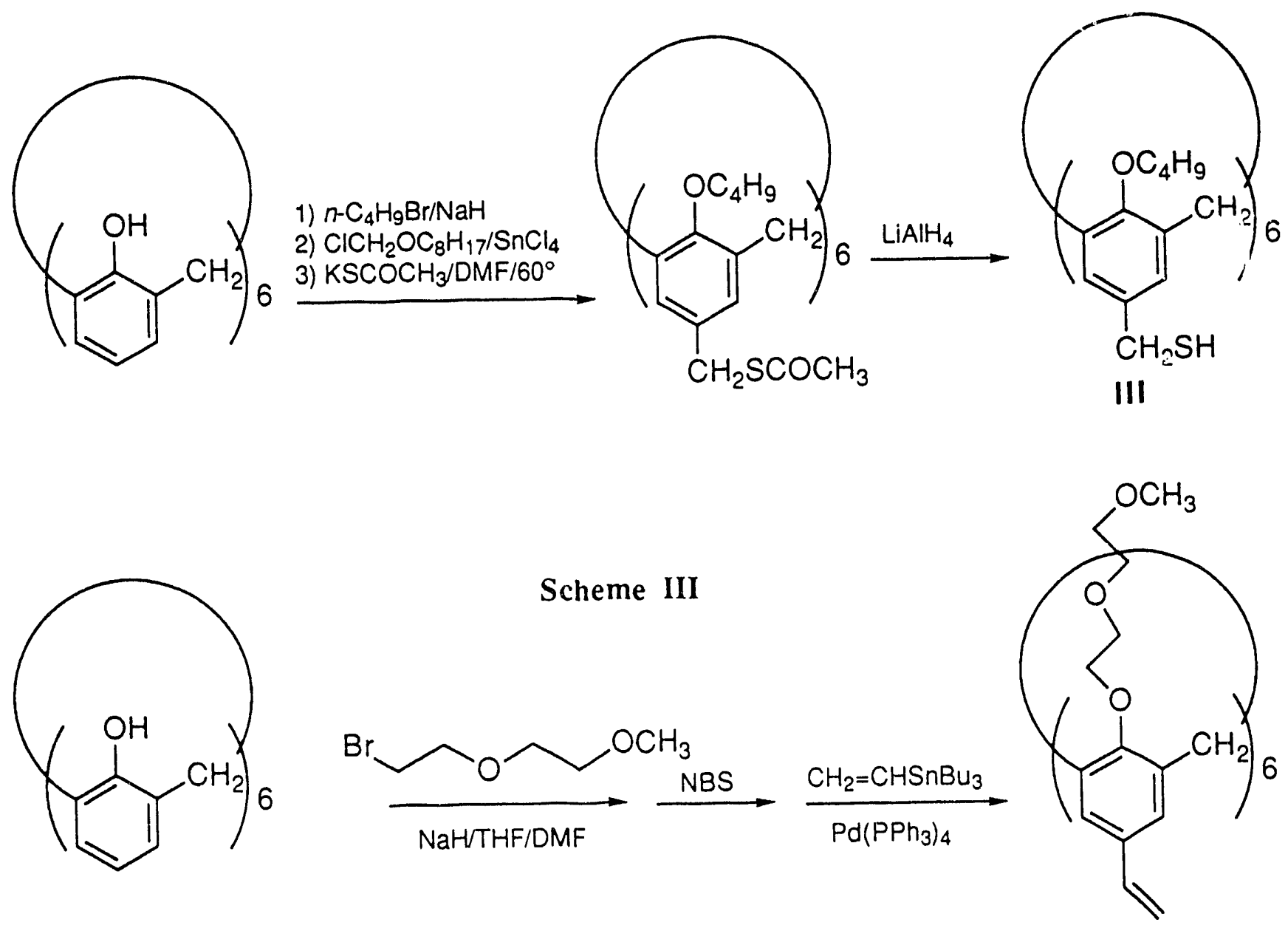

IV 
was synthesized via sequential alkylation of $37,38,39,40,41,42$-hexahydroxycalix[6]arene with 1-bromobutane, chloromethylation, thioester formation and reduction (Scheme II). Alkylation of the parent calix [6]arene framework with 3,6-dioxa-1-heptyl bromide, followed by bromination and vinylation afforded the desired styryl monomer IV (Scheme III). Each of these calixarenes have now been fully characterized by ${ }^{1} \mathrm{H}$ NMR spectroscopy and by elemental analysis or high resolution mass spectrometry.

II. Monolayer Properties. The monolayer properties that were found for each of these polymerizable calix[6]arenes were similar to those found for analogous $O$-alkylated, paramercurated calix[6]arenes. 6,7 Specifically, each calix[6]arene produced stable and relatively noncompressible monolayers at the gas-water interface. The limiting areas for I-IV (extrapolated area per molecule to zero surface pressure) were $155 \pm 10 \AA^{2}, 200 \pm 10 \AA^{2}, 158 \pm 10 \AA^{2}$, and $155 \pm$ $10 \mathrm{~A}^{2}$ per molecule, respectively; the corresponding collapse pressures were $56,55,16$, and 25 $\mathrm{dyn} / \mathrm{cm}$. The limiting areas that were observed for I, III, and IV are in excellent agreement with that predicted from CPK models ( $154 \AA^{2} /$ molecule), if it is assumed that each calixarene lies at the air-water interface in a hexagonally packed array and that all of the polar moieties are in contact with the water surface; i.e., the pore axis lies perpendicular to the water surface. The somewhat larger limiting area that was found with II is a likely consequence of some of the hydrophopbic methyldisulfide groups being positioned alongside the calix[6]arene core.

III. Polymerization Behavior At The Gas-Water Interface. The following is a brief summary of the salient polymerzation features of these calix[6]arenes. A manuscript that will describe, in detail, the synthesis, monolayer properties and polymerization behavior of these compounds is now in preparation.

a) Polymerization of Calix[6]arene I. In contrast to surface pressure/area isotherms that were observed for I over pure water, monolayers that were formed over $10^{-4} \mathrm{M}$ 
poly(allylamine) (PAA, MW=65,000) were found to be more compressible and expanded. In addition, these isotherms showed some hysteresis. However, after three successive compressionexpansion cycles, the surface pressure/area isotherms were very similar to that observed for I over pure water. We presently attribute this behavior to an annealing process that is due to reversible acid-base interactions between the calix[6]arene monolayer and the PAA. We also presume that these acid-base interactions are maximized at the end of such annealing. In order to judge the effectiveness of this polymerization, we have measured the film's cohesiveness in the presence and in the absence of PAA via surface viscosity measurements. ${ }^{7}$ As expected, PAA led to a substantial increase in the film's viscosity; i.e., the monolayer fully maintained a surface pressure of 20 dyn $/ \mathrm{cm}$ after exposure to a slit opening of $4-\mathrm{mm}$. In addition, examination of a transferred monolayer of PAA-stabilized-I by X-ray photoelectron spectroscopy has provided direct evidence for acid-base interaction. Specifically, the molar ratio of $\mathrm{CO}_{2}-/ \mathrm{NH}_{3}+$ was ca.1.0; the ratio of $\mathrm{NH}_{3}+/ \mathrm{NH}_{2}$ was ca. 3.0 .

b) Polymerization of Calix[6]arene II. Brief exposure of compressed monolayers of II, which were held at a constant surface area of $155 \AA^{2} /$ molecule, to ultraviolet light ( $254 \mathrm{~nm}$ ) led to a decrease in surface pressure from $19 \mathrm{dyn} / \mathrm{cm}$ to $9.0 \mathrm{dyn} / \mathrm{cm}$ after $5 \mathrm{~min}$. Additional UV exposure for $20 \mathrm{~min}$ resulted in a decrease of ca. $0.7 \mathrm{dyn} / \mathrm{cm}$. Surface viscosity measurements established that this ultraviolet treatment affords a highly viscous film; i.e., only a 0.2 dyn $/ \mathrm{cm}$ decrease in surface pressure was observed over a $2 \mathrm{~h}$ period, when exposed to a 4 -mm slit. In contrast, a complete loss of surface pressure was observed for compressed monolayers of II after $5 \mathrm{~min}$ if they were not UV-treated. The initial surface pressure used for measuring the surface viscosity of non-irradiated films of II was $19 \mathrm{dyn} / \mathrm{cm}$.

\section{c) Polymerization of Calix[6larene III. Compressed monolayers of III were} polymerized over a basic subphase $(9.7 \mathrm{dyn} / \mathrm{cm}, \mathrm{pH} 11, \mathrm{NaOH})$ by allowing them to air-oxidize for $20 \mathrm{~min}$. After this time period, the surface pressure was found to decrease to $8.7 \mathrm{dyn} / \mathrm{cm}$. 
Surface viscosity measurements further revealed that such treatment results in the formation of a highly viscous film. Similar results were obtained when a pure water subphase (pH 5.5) was used. In this case, the time of exposure to air was extended to $1.5 \mathrm{~h}$.

d) Polymerization of Calix [6]arene IV. In contrast to I-III, which maintained an area per molecule that was similar to that found in the non-polymerized state, photopolymerization of IV resulted in its removal from the gas-water interface. Specifically, UV-treatment of a compressed monolayer of IV, which was maintained at a constant area of $155 \AA^{2} /$ moleclule (initial surface pressure of $20 \mathrm{dyn} / \mathrm{cm}$ ), resulted in the complete loss of surface pressure after $13 \mathrm{~min}$. A similar experiment that was carried out at a constant surface pressure of $20 \mathrm{dyn} / \mathrm{cm}$, resulted in substantial film contraction; i.e., an initial surface area of $155 \AA^{2} /$ molecule at 20 dyn/cm was reduced to $85 \AA 2 /$ molecule after $5 \mathrm{~min}$. Further irradiation reduced the occupied area/molecule to ca. $45 \AA^{2}$. Apparently, polymerization of IV results in the "lifting off" of the film from the water surface into air, and a "folding back" into a multilayered structure. Because of the inability of IV to maintain monolayer coverage upon photopolymerization, this calix[6]arene was not investigated further.

IV. Langmuir-Blodgett Multilayers. All attempts that were made ar transfering monolayers of PAA/I to a glass microscope slide (vertical transfer from water to air) gave poor results; i.e., transfer ratios (defined as the decrease in monolayer area at the gas-water interface divided by thi zeometrical surface area of the substrate that passes through the interface) were typically on the order of ca. 0.3. Although III appeared to form reasonable Y-type multilayers, as judged by the transfer ratios (close to 1.0 for water to air, and for air into water) visual inspection of the surface after the transfer of 5 monolayers revealed striations. Because of these striations. such LB films were judged to be inherently unstable and were not pursued further.

In contrast to the difficulties that were experienced in forming LB films from PAA/I and III, we have found that II showed excellent LB transfer characteristics. Multilayers of II that 
were built on a silicon wafer gave transfer ratios of $1.06 \pm 0.13$ (water to air) and $0.94 \pm 0.09$ (air into water) and a surface that appeared to be uniform by visual inspection. Both types of transfer were made using a surface pressure of $24 \mathrm{dyn} / \mathrm{cm}$ and a vertical transfer speed of $0.8 \mathrm{~cm} / \mathrm{min}$. Careful examination of such film by ellipsometry (after the transfer of $3,5,7,11,17$, and 21 monolayers) showed a film thickness of ca. $20 \pm 2 \AA$ per calixarene monolayer, which is in agreement with that predicted from CPK models. Irradiation of a 21 -layered LB film for 7 min led to an apparent decrease in overall film thickness of ca. 20\%. Also, in contrast to a non-UV irradiated film, which was completely removed by washing with chloroform and methanol, only ca. $24 \%$ of a UV-treated film could be removed by similar washing (ellipsometry). Repeated washings did not remove any additonal film from the silicon wafer.

On the basis of it surfactant characteristics, and its polymerization and LB-multilayer forming properties, calix[6]arene II was considered to be well-suited for the fabrication of perforated LB composites.

\section{Fabrication of Composite Films Based On II and Permeability Towards} $\mathrm{He}, \mathrm{N}_{2}$, and $\mathrm{SF}_{6}$. Composite membranes were fabricated by transferring 26 (and also 50) monolayers of II to $25 \mu \mathrm{m}$-thick Celgard supports (a stretched form of polypropylene having nominal pores of ca. $4000 \times 400 \AA$ ). The permeability properties of these composites were then determined, using $\mathrm{He}, \mathrm{N}_{2}$ and $\mathrm{SF}_{6}$ as permeants. Although a significant reduction in permeability was observed toward all of these gases, relative to the parent Celgard support, the changes in permselectivity were not significant (Table I). Similar results were obtained using Nuclepore membranes (track-etched polycarbonate filters that contain $300 \AA$ ) as support material. Careful examination of these composites, by use of a JEOL 6300 scanning electron microscope (equipped with a field emission so:arce) revealed the presence of film defects. Apparently, the transferred monolayers are unable to effectively traverse all of the macropores that are present on the surface of the film. 
In an effort to minimize defect formation, poly[1-(trimethylsilyl)-1-propyne] (PTMSP) was then examined as support material.8,9 Cast films of this polymer are known to possess extraordinarily high permeability due to a high internal free volume and a glassy state. Transfer of 12 monolayers of I to $14 \mu \mathrm{m}$-thick cast films of PTMSP gave composites having barrier properties toward $\mathrm{He}, \mathrm{N}_{2}$, and $\mathrm{SF}_{6}$ that are also presented in Table I. In striking contrast to those membranes that were prepared from the macroporous supports, a significant decrease in permeability was accompanied by a substantial increase in permselectivity. The $\mathrm{He}_{\mathrm{SSF}}$ selectivity, which was $>440$ for the 12-layer composite, is particularly noteworthy. The fact that the ratios of $\mathrm{He} \mathrm{SF}_{6}$ $(>440)$ and $\mathrm{He} / \mathrm{N}_{2}(17)$ are much higher than that which is predicted by Graham's law (i.e., $\mathrm{He} / \mathrm{SF}_{6}=6 ; \mathrm{He} / \mathrm{N}_{2}=2.6$ ) provides compelling evidence that the pores are of molecular dimensicns, and that permeation is governed by a sieving action of the composite and not by Knudsen diffusion. ${ }^{10}$ Examination of CPK models indicate that $\mathrm{SF}_{6}$ is too large to pass through the pore of $\mathbf{I}$. Thus, any of the $\mathrm{SF}_{6}$ that does pass through this composite must diffuse across interstitial pores. In contrast, nitrogen and helium have diameters which should permit their passage through I. Although we cannot presently assign the fraction of $\mathrm{He}$ and $\mathrm{N}_{2}$ that diffuse across molecular versus interstitial pores, the selectivity features of this composite clearly show that its pore structure is unique, compared with standard LB-films made from stearic acid, which do not exhibit sieving properties. ${ }^{11}$

Efforts that have been made to stabilize PTMSP/I by UV treatment ( $254 \mathrm{~nm}, 7 \mathrm{~min}$ ) have resulted in a significant reduction in permselectivity (Table I). Apparently, the integrity of the LB suprastructure cannot be fully maintained under these conditions; i.e., defects are created as a consequence of the two-dimensional polymerization and/or the photodecomposition of the support.

The results of these p:eliminary studies will be published shortly, in Communication form, in the Journal of the American Chemical Society. A full account of this work, including the synthetic chemistry, membrane fabrication and permeation measurements, is now in preparation. 
Table I. Flux of $\mathrm{He}, \mathrm{N}_{2}$, and $\mathrm{SF}_{6}$ Across Membrane Composites ${ }^{\mathrm{a}}$

\begin{tabular}{lcllcc}
\hline Membrane & $\begin{array}{c}\text { Monolayers } \\
\text { of } \mathrm{II}^{\mathrm{b}}\end{array}$ & $\begin{array}{c}\text { Pressure } \\
(\mathrm{atm})\end{array}$ & $\begin{array}{l}\mathrm{He} \\
\ldots\end{array}$ & $\begin{array}{c}\mathrm{N}_{2} \\
\left(\mathrm{~cm}^{3} / \mathrm{cm}^{2}-\mathrm{s}-\mathrm{cm} \mathrm{Hg}\right)\end{array}$ \\
\hline Celgard & 0 & 0.03 & $2800 \times 10^{-4}$ & $1100 \times 10^{-4}$ & $540 \times 10^{-4}$ \\
Celgard/II & 26 & 0.03 & $31 \times 10^{-4}$ & $24 \times 10^{-4}$ & $14 \times 10^{-4}$ \\
Celgard/II & 50 & 0.09 & $11 \times 10^{-4}$ & $\ldots-.-$ & $5.2 \times 10^{-4}$ \\
Nuclepore & 0 & 0.03 & $630 \times 10^{-4}$ & $250 \times 10^{-4}$ & $130 \times 10^{-4}$ \\
Nuclepore/II & 26 & 0.20 & $9.6 \times 10^{-4}$ & $4.0 \times 10^{-4}$ & $1.9 \times 10^{-4}$ \\
PTMSP & 0 & 0.70 & $530 \times 10^{-6}$ & $540 \times 10^{-6}$ & $310 \times 10^{-6}$ \\
PTMSP/II & 12 & 0.70 & $96 \times 10^{-6}$ & $5.8 \times 10^{-6}$ & $<0.22 \times 10^{-6}$ \\
PTMSP/II & 24 & 0.70 & $54 \times 10^{-6}$ & $4.0 \times 10^{-6}$ & $<0.22 \times 10^{-6}$ \\
PTMSP/II & 24 & 0.70 & $47 \times 10^{-6}$ & $2.0 \times 10^{-6}$ & $<0.22 \times 10^{-6}$ \\
PTMSP/II & 24 & 0.70 & $20 \times 10^{-6}$ & $1.9 \times 10^{-6}$ & $1.9 \times 10^{-6}$ \\
PTMSPd & 0 & 0.70 & $150 \times 10^{-6}$ & $14 \times 10^{-6}$ & $4.1 \times 10^{-6}$ \\
\hline
\end{tabular}

aNormalized for pressure and area $\left(1.2 \mathrm{~cm}^{2}\right)$; all PTMSP film were ca. $14 \mu \mathrm{m}$ in thickness.

In all cases, the permeant pressure was applied to the calixarene side of the membrane. ${ }^{b}$ Transfer ratios Celgard were $1.09 \pm 0.05$ and $0.90 \pm 0.02$ on the up- and down-trips, respectively; for Nuclepore membranes, they were $1.07 \pm 0.03$ and $1.02 \pm 0.03$, respectively. The up- and downtransfer ratios for PTMSP were $1.07 \pm 0.03$ and $0.98 \pm 0.06$, respectively. cUV-treated composite. dUV-rreated support. 
VI. Permselectivity of Composites Based On V/PTMSP. In preliminary studies calix[6]arene $\mathbf{V}$ was synthesized according the methods outlined in Scheme IV. This target molecule was chosen because it was felt that it would have the "right" hydrophobic/hydrophilic balance such that it would form stable monolayers at the gas-water interface, and that it would yield Y-type LB film. Although this molecule is non-polymerizable, it was of interest to see if we could find other cilix[6]arenes that could be used in constructing permselective composite membranes. In preliminary studies, we have found that $\mathbf{V}$ does form stable and non-compressible monolayers at the gas-water interface, having a collapse pressure of $55 \mathrm{dyn} / \mathrm{cm}$ and a limiting area of $150 \pm 10$ $\AA^{2} /$ molecule. We have also found that it forms $\mathrm{Y}$-type monolayers and that a composite, made from 12 layers of $V$ on 14 mm-thick PTMSP film, exhibits significant permselectivity; i.e., the rato of $\mathrm{He}_{\mathrm{SF}} 6$ flux was ca. 400.

\section{Scheme IV}
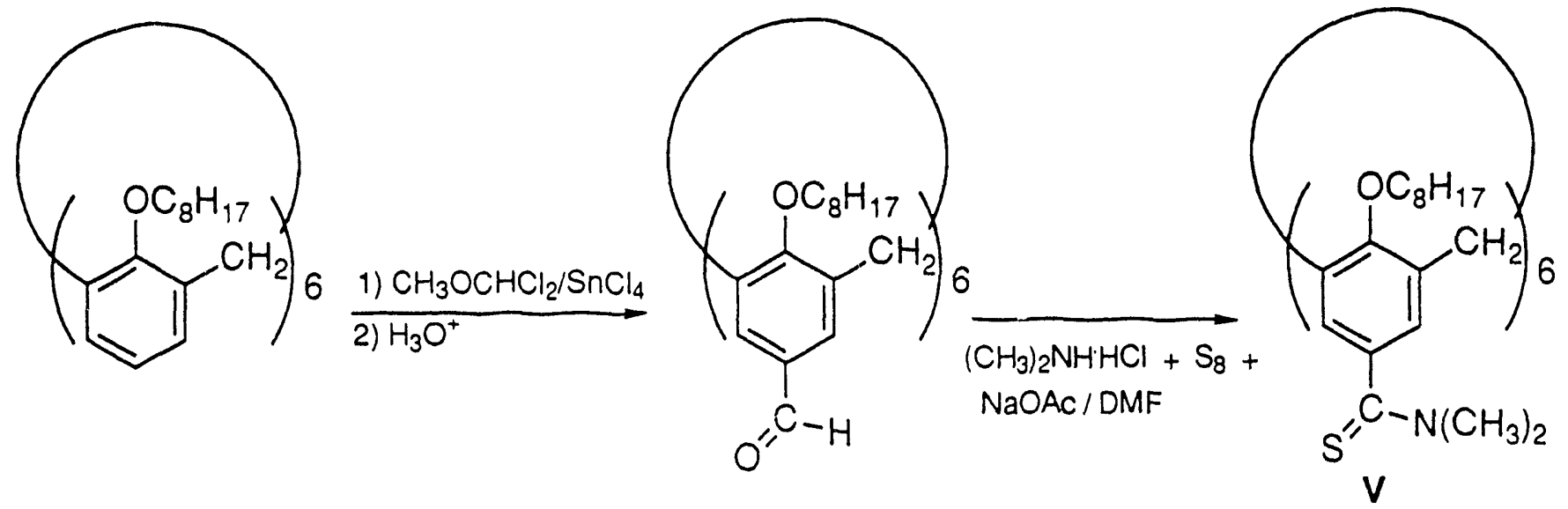
VII. Derivative Studies. In this section we report derivative studies that have come out of the above efforts. Reprints, which describe this work in greater detail, are included.

\section{a) A Convenient Method For Measuring Pervaporation Through Monolavers At}

The Gas-Water Interface. A convenient method has been devised for measuring the pervaporation of tetrahydrofuran, cis-2,5-dimethyltetrahydrofuran, and trans-2,5-dimethyltetrahydrofuran through monolayers derived from cetyl alcohol and oleoyl alcohol at the gas-water interface. Permeation data that have been obtained demonstrate that the release of these ethers into the vapor phase is significantly retarded by the presence of these surfactant monolayers, and that the film barrier is a function of its packing density and the specific structure of the surfactant. These pervaporation data further show that the flux rates are strongly dependent on the structure and composition of the permeant.

b) Octopus Molecules At The Air-Water Interface. Alkylation of 37, 38, 39, 40, 41, 42-hexahydroxycalix[6]arene with a series of brominated poly(ethylene glycol) monomethyl ethers [i.e., $\mathrm{CH}_{3} \mathrm{O}\left(\mathrm{CH}_{2} \mathrm{CH}_{2} \mathrm{O}\right)_{11} \mathrm{CH}_{2} \mathrm{CH}_{2} \mathrm{Br}$, where $\mathrm{n}=0,1,2$, and 3] yields octopus molecules $1 \mathrm{a}, 1 \mathrm{~b}, 1 \mathrm{c}$ and $1 \mathrm{~d}$, respectively. Examination of the monolayer properties of $1 \mathrm{~b}$ and $1 \mathrm{c}$ reveals that their polyether "tentacles" lie at the air--water interface at low surface pressures, and are forced down into the subphase when the film is compressed. Similar behavior has been observed for 1d, but only over a saturated aqueous $\mathrm{NaCl}$ subphase. In the condensed state, calixarenes 1a-1d have their tentacles tucked beneath their aromatic core. For calix[6]arene 1a, the polyether moieties have been found to be too short to be moved back and forth between surface of water and the subphase. Introduction of bulky p-tert-butyl groups onto the upper rim of the calix[6]arene framework significantly reduces intermolecular polyether interactions. Qualitatively, similar behavior has been found with analogous calix[4]arene-based octopi. In principle, the ability to control the orientation of such tentacles should allow one to fine-tune the octopus's interaction with 
a guest ion or molecule. It could, therefore, provide the basis for novel means of separating ions and/or molecules.

c) Pinched Cone Conformers of Calix[4]arene. The cone conformational isomer of 5,11,17,23-tetracarboxy-25,26,27,28-tetra-n-octylcalix[4]arene (2) and 5,11,17,23tetracarboxamido-25,26,27,28-tetra- $n$-octylcalix[4]arene (3) have been synthesized and found to exist as equilibrating $\mathrm{C}_{2 v}$ structures. Evidence in support of this conclusion has been obtained from variable temperature ${ }^{1} \mathrm{H}$ NMR spectroscopy, using $\mathrm{CDCl}_{2} \mathrm{CDCl}_{2}$ as the solvent. These findings represent the first experimental evidence for the existence of $\mathrm{C}_{2 \mathrm{v}}$ conformational isomers of a calix[4]arene in solution. The free energy of activation for the interconversion, calculated from the temperature at which the aromatic protons coalesce from iwo singlets to one, was 14.1 $\mathrm{kcal} \mathrm{mol}-1$ for 2 at $45^{\circ} \mathrm{C}$, and $13.3 \mathrm{kcal} \mathrm{mol}^{-1}$ for 3 at $-4^{\circ} \mathrm{C}$. The appearance of 2 and $\mathrm{s}$ as $\mathrm{C}_{4 \mathrm{v}}$ isomers in DMSO- $\mathrm{d}_{6}$, tc gether with a large deuterium isotope effect on $\mathrm{T}_{\mathrm{c}}$ in $\mathrm{CDCl}_{2} \mathrm{CDCl}_{2}\left(\mathrm{~T}_{\mathrm{c}}\right.$ is raised $\sim 25^{\circ}$ for 2 and $\sim 19^{\circ}$ for 3 ) and the appearance of a methy. ester analog of 2 as a $\mathrm{C}_{4 \mathrm{v}}$ structure in $\mathrm{CDCl}_{2} \mathrm{CDCl}_{2}$, provide strong evidence that internal hydrogen bonding contributes, significantly, to the barrier for interconversion.

\section{d) Synthesis And Alkali Metal Binding Properties of 'Upper-Rim' Functionalized}

Calix[4]arenes. Alkylation of 25,26,27, 28-tetrahydroxycalix[4]arene with 1-bromooctane afforded the corresponding tetra-n-octyloxyether, which was readily isolated as the cone isomer. Friedel-Crafts acylation $\left(\mathrm{CH}_{3} \mathrm{COCl}\right)$ of this tetraether afforded 5,11,17,23-tetraacetyl25,26,27,28-tetrakis-(1-n-octyloxy)calix[4]arene (4); subsequent haloform oxidation, and esterification $\left(\mathrm{CH}_{2} \mathrm{~N}_{2}\right)$, yielded 5,11,17,23-tetracarboxymethyl-25,26,27,28-tetrakis-(1-noctyloxy)calix[4]arene (5). 5,11,17,23-Tetracarboxamido-25,26,27,28-tetraoctyloxycalix[4]arene (6) was prepared by bromination of the starting tetra- $n$-octyloxyether (NBS), followed by sequential displacement with cyanide and hydrolysis. Calix[4]arenes 4-6 proved to be effective in extracting $\mathrm{Li}^{+}, \mathrm{Na}^{+}, \mathrm{K}^{+}$, and $\mathrm{Cs}^{+}$picrates from chloroform into water. Unlike the extracting 
behavior of a previously reported lower-rim ester derivative, however, each showed similar extrability of sodium and potassium picrates, but significantly reduced efficacy toward lithium and cesium salts. Equilibrium extraction constants $\left(\mathrm{K}_{\mathrm{e}}\right)$ for each calix[4]arene type are reported.

\section{BIBLIOGRAPHY}

(1) Kunitake, T.; Ueno, T., Chem. Letters, 1990, 1927.

(2) Regen, S. L.; Yamaguchi, K.; Samuel, N. K. P.; Singh, M., J. Am. Chem. Soc., 1983, 105,6354 .

(3) Capozzi, G.; Modena, G., "Oxidation of Thiols" In "The Chemistry of The Thiol Group", Patai, C. S., Ed.; Wiley: New York, 1974; Part Z, p 785.

(4) Ahmad, J.; Astin, K. B., Colloids and Surfaces, 1990, 49, 281.

(5) Conner, M.; Kudelka, I.; Regen, S. L., Langmuir, 1991, 7, 982.

(6) Markowitz., M. A.; Bielski, R.; Regen, S. L., J. Am. Chem. Soc., 1988, 110, 7545.

(7) Markowitz, M. A.; Janout, V.; Castner, D. G.; Regen, S. L., J. Am. Chem. Soc., 1989, $111,8192$.

(8) Masuda, T.; Isobe, E.; Higashimura, T.; Takada, K., J. Am. Chem. Scc., 1983, 105, 7473.

(9) "Polymers For Gas Separation", Toshima, N., Ed., VCH Publishing, New York, 1992.

(10) Keizer, K.; Uhlhorn, R. J. R.; Van Vuren, R. J.; Burggraaf, A. J., J. Membr. Sci., 1988, $39,285$.

(11) Gaines, G. L., Jr.; Ward, W. J. III, J. Colloid Interface Sci., 1977, 60, 210. 


\section{STAFFING}
Professor S. L. Regen
07/01/87--present
Dr. Ivo Kudelka
$10 / 01 / 89--10 / 31 / 91$
Dr. Vaclav Janout
07/01/88-09/30/89
Mr. Mark Conner
$01 / 01 / 90-09 / 30 / 92$
Dr. Peter Dedek
11/01/91-present
Dr. Jiayi Zhu
08/01/92-present

\section{PUBLICATIONS ACKNOWLEDGING DOE SUPPORT UNDER GRANT DE-FG02-85ER13403}

(1) "Octopus Molecules At The Air-Water Interface. Mechanical Control Over Tentacle

Orientation", M. Conner, I. Kudelka, S. L. Regen, Langmuir, 1991, 7, 982.

(2) "Pinched Cone-Conformers of Calix[4]arenes", M. Conner, V. Janout, S. L. Regen, J. Am. Chem. Soc., 1991, 113, 9670.

(3) "Synthesis and Alkali Metal Binding Properties of 'Upper-Rirn' Functionalized Calix[4]arenes", M. Conner, V. Janout, and S. L. Regen, J. Org. Chem., 1992, 57, 3744.

(4) "A Convenient Method For Measuring Pervaporation Through Monolayers At The GasWater Interface", M. Conner, S. L. Regen, Langmuir, 1992, 8, 2347.

(5) "Molecular Sieving By A Perforated Langmuir-Blodgett Film", M. Conner, V. Janout, S. L. Regen, J. Am. Chem. Soc., in press. 

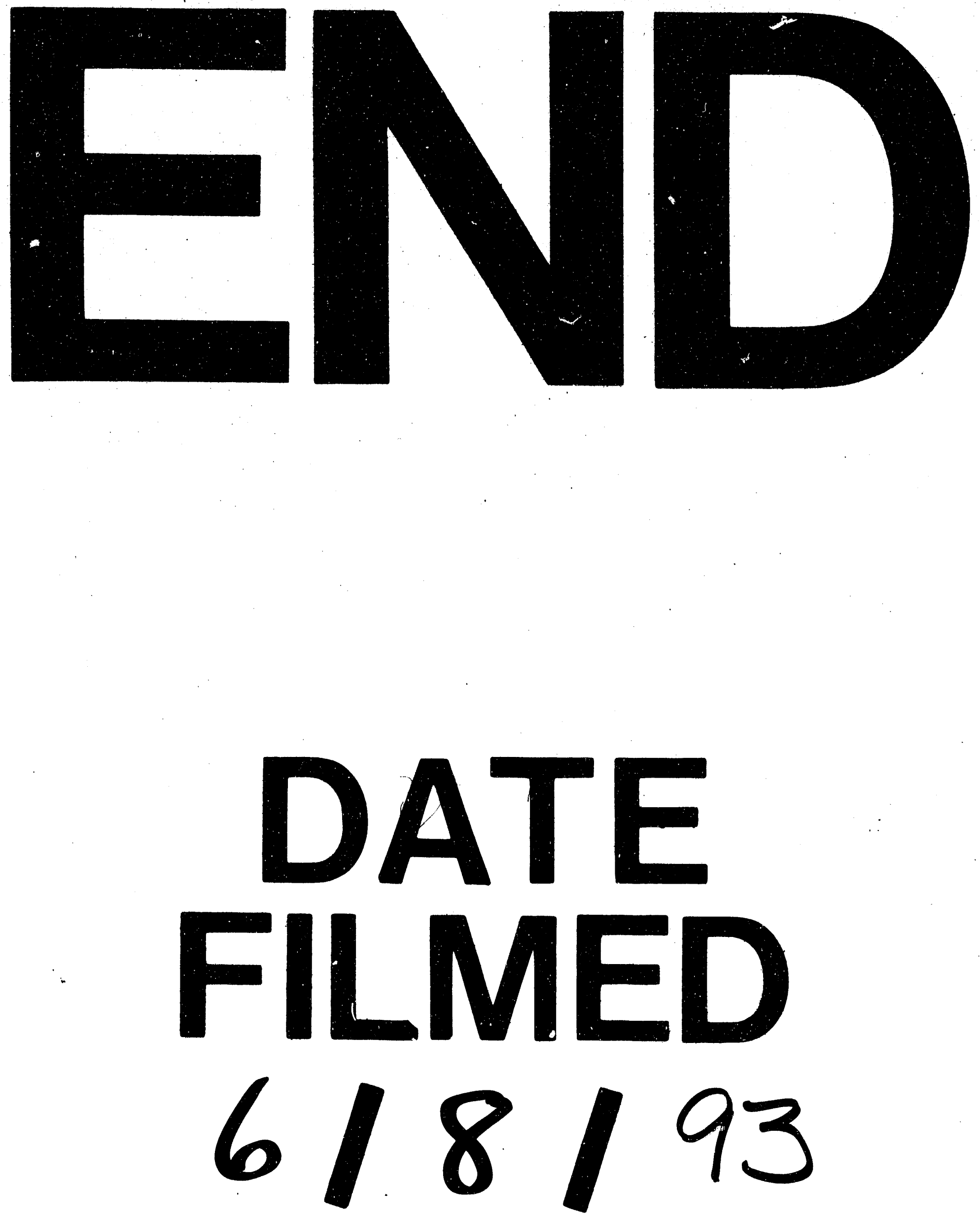
